in the lower exposure group. We did point out that at Deer Park the higher exposure group was first exposed earlier than the lower exposure group.

Ross also feels that we made no effort to distinguish between the effects of $\mathrm{ECH}$ alone from those of $\mathrm{ECH}$ in combination with allyl chloride. We did, in fact, do this. On page 276 of our article where we point out that the only raised cardiovascular disease SMR was for workers with moderate to heavy exposure to $\mathrm{ECH}$ and who had probable exposure to allyl chloride $(S M R=120 \cdot 7)$. For workers without probable exposure to allyl chloride the SMRs were much lower.

Finally, Ross quotes from page 276 of our article "There is little in human or animal experience to suggest a relation between allyl chloride and cardiovascular disease." The context for this was our review of the very few publications relating to allyl chloride. It remains to be seen what further research might add.

1 Marsh G, Enterline PE, McCraw D Mortality patterns among petroleum refinery and chemical plant workers. Am J Ind Med (in press).

\section{Asbestos: a chronology of its origins and health effects}

Sir,-We were interested in Murray's article $(1990 ; 47: 361-5)$ about asbestos. Recently we have completed the first part of a study on mesothelioma deaths in Leeds and through our research have become aware of the important contribution of Leeds' doctors to the asbestos story.

Dr Ian M D Grieve, a general practitioner working in the Armley area of Leeds in the 1920 s, was aware of the detrimental effect of asbestos on the health of some of his patients who worked at a local factory that produced insulation mattresses for steam engines. These were made from blue asbestos, which had been in use at the factory from 1906 . He submitted an $\mathrm{MD}$ thesis to Edinburgh University on the subject of asbestosis in September $1927 .^{1}$

In this he defined asbestosis as "a chronic pneumokoniosis affecting all asbestos workers within five years, the fibrosis being basal, beginning on the right side and being accompanied by diffuse pleural adhesions, whilst the upper lobes are emphysematous, the symptoms being early dyspnoea with dry cough followed by wasting, anorexia and weakness, without fever, night sweats or Tubercle Bacilli in the Sputum, and terminating fatally in 20 to 30 years from exhaustion and intercurrent disease." Grieve described 15 cases of asbestosis at various stages including one woman who had died and for whom there was available postmortem material. In nine of the 15 cases, he was unable to find evidence of tuberculosis which led him to the conclusion that "pulmonary tuberculosis does not supervene and is not the ultimate cause of death."

This conclusion was documented in $1927^{2}$ in a report of the BMA annual meeting in Edinburgh, where Professor Stuart McDonald, professor of pathology at the University of Durham, commenting on Grieve's case, declared "there was in the sections examined a considerable degree of fibrosis without apparent tuberculosis. The immediate cause of death in that case was a terminal bronchopneumonia," This case would predate the case of Seiler to which Murray makes reference.

Interestingly Dr A C Haddow, Grieve's senior partner, described the clinical aspects of asbestos ${ }^{15}$ at a BMA meeting in $1929^{3}$ and quoted a case "in which the curious bodies were found in a man who was not employed in the industry, but who lived next door to an asbestos factory. The result was confirmed by Prof J M Stewart (Leeds)."

As Professor of Pathology at Leeds University, Stewart's interest in asbestosis included the development of techniques for demonstrating the peculiar bodies in material from lung puncture about which he published a paper together with Haddow in $1929 .{ }^{4}$

The contribution of Grieve, Stewart, and Tattersall, a Leeds radiologist, to his understanding of the nature of asbestos ${ }^{15}$ was formally acknowledged by E R A Merewether in his influential "report on the effects of asbestos dust on the lungs and dust suppression in the asbestos industry" published in $1930 .^{5}$

We are about to start the second phase of our research into mesothelioma deaths in Leeds in which the relative contributions of differing types of exposure to asbestos in the development of mesothelioma will be examined.
A copy of the report "Leeds mesothelioma deaths 1971-87" can be obtained from Dr Martin Schweiger, medical officer for environmental health and consultant in public health medicine, St Mary's House, St Mary's Road, Leeds LS7 3JX.

\section{LORNA ARBLASTER EDWARD RENVOIZE PAUL HATTON MARTIN SCHWEIGER University of Leeds, 32 Hyde Terrace, Leeds LS2 9LN, Yorkshire} Department of Public Health Medicine,

1 Grieve IMD. Asbestosis. Edinburgh: University of Edinburgh, 1927. (MD thesis.)

2 McDonald S. Histology of pulmonary asbestosis. Br Med J 1927;2:1025-6.

3 British Medical Association Occupational Diseases. Lancet 1929;ii:231.

4 Stewart MJ, Haddow AC. Demonstration of the peculiar bodies of pulmonary asbestosis ("'asbestosis bodies") in material obtained by lung puncture and in the sputum. Journal of Pathology and Bacteriology 1929;32:172.

5 Merewether ERA, Price CW. Report on the effects of asbestos dust on the lungs and dust suppression in the asbestos industry. London: HMSO, 1930.

\section{Blood lead concentration, renal function, and blood pressures in London civil servants}

Sir,-The paper of Staessen et al $(1990 ; 47: 422-7)$ is typical of a widening gulf between North American and European views as to the validity and importance of the relation between exposure to lead in the general population and blood pressure. Europeans have described positive relations between blood pressure and the concentration of lead in blood, but tend to dismiss them as trivial and unimportant-mainly because the relations become attenuated upon control for various confounders. ${ }^{12}$ Reports originating from North America basically report the same magnitude of relation, ${ }^{3-5}$ but interpret the findings as being of significant public health importance because of the morbidity potentially attributable to the levels of lead exposure observed in the population. ${ }^{6}$ I suggest that both views are missing the mark.

With respect to controlling for confounders, I have previously alluded to 